\title{
REATTACHMENT OF THE GREATER TROCHANTER AFTER HIP REPLACEMENT
}

\author{
B. M. WROBLEWSKI, PHILIP SHELLEY \\ From the Centre for Hip Surgery, Wrightington Hospital, Wigan
}

\begin{abstract}
A method of performing a biplanar intracapsular trochanteric osteotomy with a Gigli saw was designed and tested prospectively in $\mathbf{4 3 1}$ cases of Charnley low friction arthroplasty. Three methods of trochanteric reattachment were tested, and a double cross-over wire with a compression spring was best; this method was successful in 222 out of 226 patients $(\mathbf{9 8 . 2} \%$ ), of which half were revision operations. Adduction seemed to be the main movement leading to trochanteric detachment.
\end{abstract}

Exposure of the hip by trochanteric osteotomy has been an integral part of the Charnley low friction arthroplasty (LFA) since its inception. This technique facilitates both access to the joint and correct alignment of the prosthetic components. It was also a deliberate attempt to ensure that the abductor lever of the hip was retained.

This type of exposure has been criticised. Wiesman et al. (1978), for example, suggested that it prolonged the operation and increased blood loss, although others (del Sel, Brittain and Wroblewski 1981) deny this.

Various methods of trochanteric reattachment have been described and some surgeons, feeling that secure fixation is almost impossible, have suggested that trochanteric osteotomy should be used only in exceptional cases and for revision operations (Nutton and Checketts 1984).

The mechanism leading to trochanteric detachment after arthroplasty has been analysed and various methods of reattachment tested experimentally (Charnley 1979; Markolf. Hirschowitz and Amstutz 1979; Dall and Miles 1983). The general view seems to be that it is the pull of the abductors with the hip in flexion which leads to trochanteric separation.

Two clinical observations should be taken into account. First, that the natural tendency after osteotomy is for the detached trochanter to rotate anteriorly in relation to the trochanteric bed, and, in order to replace it in its anatomical position, it must be deliberately rotated posteriorly. Secondly, that once the trochanter has been replaced and even before it has been fixed, the hip can be flexed fully without any tendency towards displacement.

B. M. Wroblewski. FRCS. Consultant Orthopaedic Surgeon P. Shelley, PhD. Research Fellow

Centre for Hip Surgery, Wrightington Hospital, Wigan, Lancashire WN6 9EP. England.

Requests for reprints should be sent to Mr B. M. Wroblewski.

( 1985 British Editorial Society for Bone and Joint Surgery $0301620 \times 855158 \$ 2.00$
Adduction. however, or the combination of flexion, adduction and medial rotation of the hip will elevate the distal part of the trochanter from its bed.

A biplanar trochanteric osteotomy was probably first used by Debeyre and Duliveux (1954). More recently. Weber and Stühmer (1979) have described a "dihedral self-stabilizing" trochanteric osteotomy designed to resist rotation of the trochanter after reattachment. The advantages of this type of osteotomy are obvious. Not only is rotation resisted but anatomical replacement of the trochanter is made easier, and the surface area of the osteotomy is increased. The disadvantages are the ease with which the trochanter can be cut too deeply and the fact that the osteotomy is always extracapsular. To overcome these disadvantages a set of instruments was designed (Fig. I) and a procedure developed for performing a biplanar intracapsular osteotomy (Fig. 2). The technique has been tested in a prospective study using three different methods of trochanteric reattachment.

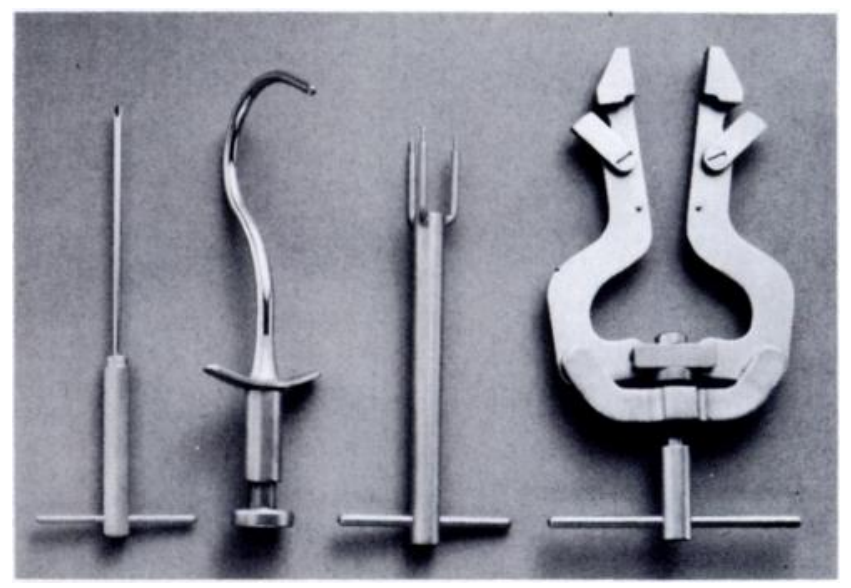

Fig. 1

Instruments designed for trochanteric osteotomy and reattachment. From left to right: a spike on a T-handle, a wire passer, a trident to help positioning of the trochanter, and a cannulated wire tightener. 


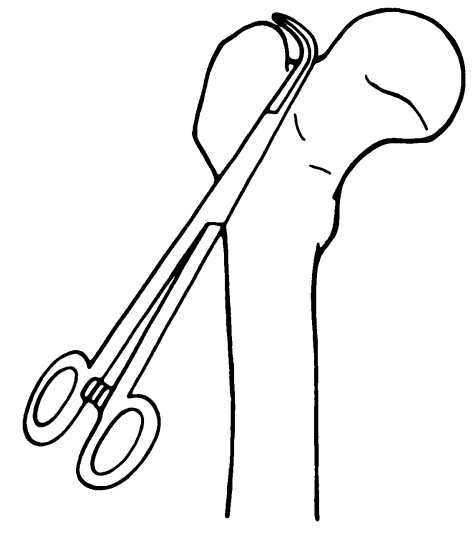

a
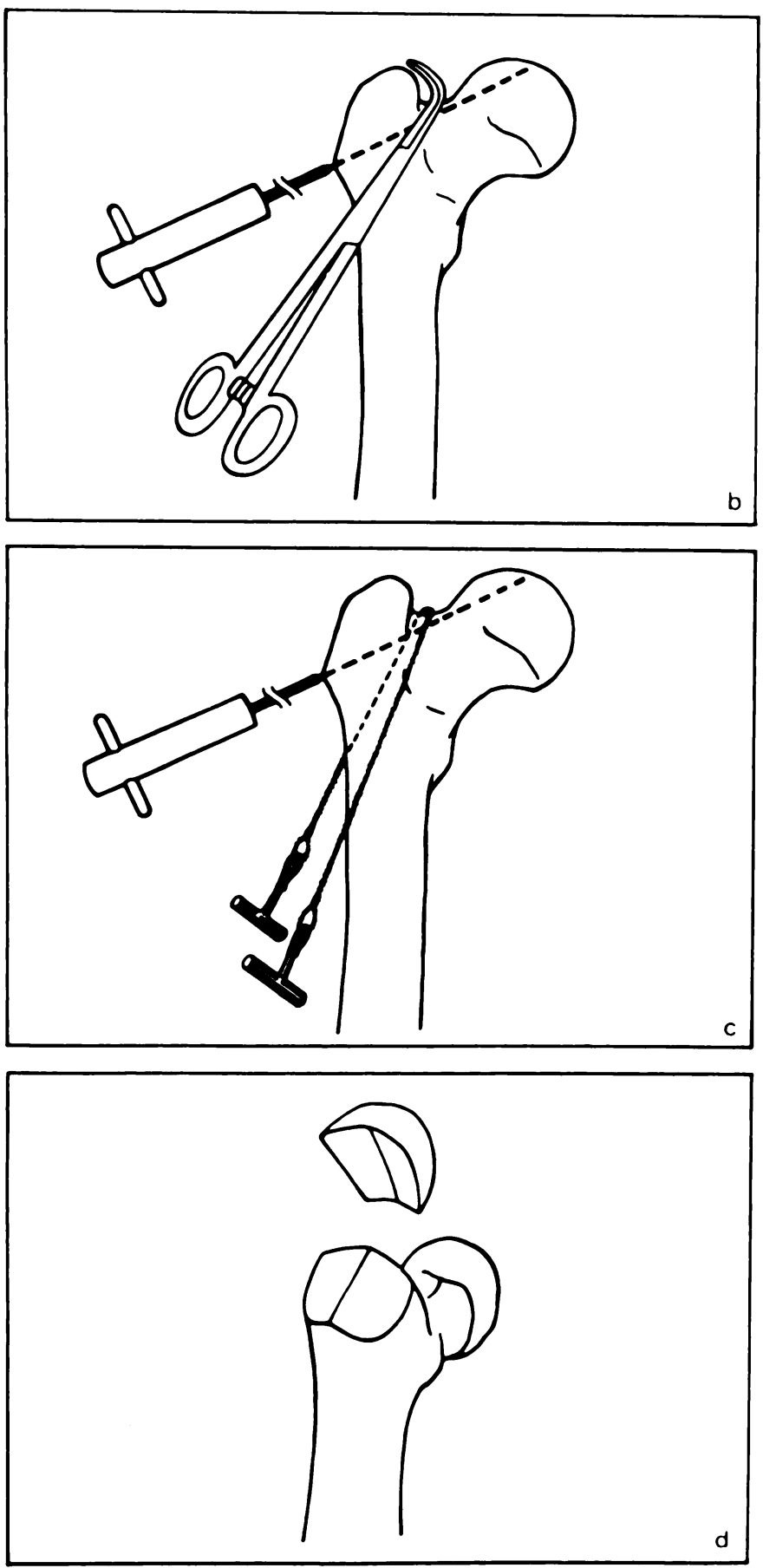

(4)

WOEבE
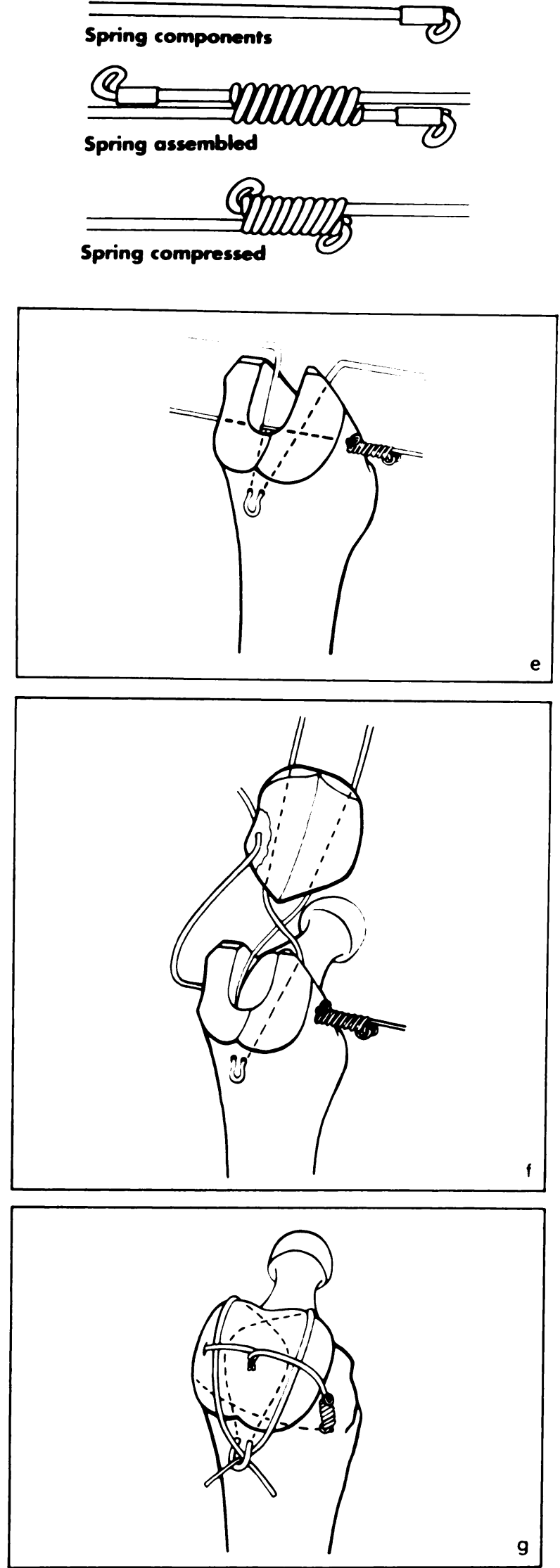

Fig. 2

The stages of trochanteric osteotomy and reattachment, using a double cross-over wire and a compression spring (upper right). Note the engagement of the loops over the coils of the spring. See text for details. 
Table I. Original diagnosis of the 431 patients treated

\begin{tabular}{|c|c|c|c|c|}
\hline & \multirow[b]{2}{*}{$\begin{array}{l}\text { Primary } \\
\text { OA }\end{array}$} & \\
\hline & & $\begin{array}{l}\text { Secondary } \\
\text { OA }\end{array}$ & $\mathbf{R A}$ & Total \\
\hline Cruciate wire & 31 & 31 & 4 & 66 \\
\hline Double and single wire & 86 & 48 & 5 & 139 \\
\hline $\begin{array}{l}\text { Double wire and com- } \\
\text { pression spring }\end{array}$ & 152 & 64 & 10 & 226 \\
\hline Total & 269 & 143 & 19 & 431 \\
\hline
\end{tabular}

OA, osteoarthritis

RA. rheumatoid arthritis

\section{PATIENTS AND METHODS}

Four hundred and thirty-one patients were treated and their original diagnoses are shown in Table I; of these, 139 were revisions of total hip arthroplasty, while 76 had previously had an operation other than arthroplasty (Table II). The average weight of the patients was $140 \mathrm{lb}$ $(63.6 \mathrm{~kg})$ in the group treated by cruciate wire, $140 \mathrm{lb}$ in the double and single wire group and $145 \mathrm{lb}(66 \mathrm{~kg})$ in the group treated by double wire and compression spring. The average age in all three groups was 58 years.

Exposure and osteotomy. With the patient lying supine and parallel with the operating table, the hip is flexed some 30 , adducted and slightly rotated medially. Any excess of subcutaneous fat tends to move posteriorly away from the line of the incision.

The skin incision, about $25 \mathrm{~cm}$ long, is made along the lateral aspect of the thigh just in front of the line of the femur; it extends as far as the anterior border of the greater trochanter and then curves posteriorly at about 30 , ending $3 \mathrm{~cm}$ proximal to the line of the anterior superior iliac spine. The deep fascia is divided in the same line, allowing access behind and proximal to the greater trochanter.

Dense areolar tissue covers the greater trochanter. It extends from the anterior border of the abductors anteriorly to the insertion of the gluteus maximus posteriorly. Distally its free border lies just proximal to the vastus lateralis ridge while proximally it blends intimately with the intermuscular septa of the abductor mass, enveloping the greater trochanter and preventing direct access to it. The greater trochanter moves freely deep to this areolar tissue and to the trochanteric bursa.
To gain access to the greater trochanter, the front of the neck of the femur and to the piriform fossa, the trochanteric bursa should be elevated proximally by inserting dissecting forceps under its free distal edge and elevating it over the abductor mass. This clears the anterior border of the abductors and the posterior aspect of the greater trochanter. With the hip flexed, adducted and medially rotated the vastus lateralis ridge is now near the centre of the exposure. Fatty tissue is retracted from the anterior part of the capsule while the hip is laterally rotated. Cutting diathermy is used just proximal to the vastus lateralis ridge to divide the soft tissues down to bone and to open the front of the hip joint. cutting transversely so that most of the anterior capsule remains attached to the greater trochanter. This exposes the front of the femoral neck from the greater trochanter laterally to near the anterior margin of the acetabulum medially.

A pair of cholecystectomy forceps is then inserted within the capsule over the superior border of the femoral neck and into the notch between the neck and the greater trochanter (Fig. 2a). This instrument then passes posteriorly close to the neck of the femur in the plane between the femur and the short lateral rotators, also retracting the anterior border of the abductors. With the cholecystectomy forceps in position, a $4 \mathrm{~mm}$ Steinmann pin on a T-handle is introduced through the centre of the greater trochanter, just below the level of the vastus lateralis ridge at an angle of about 45 to the shaft of the femur. The pin is driven into the neck of the femur just distal to the cholecystectomy forceps and pushed well up into the femoral head (Fig. 2b). The cholecystectomy forceps are now turned laterally, piercing the capsule posteriorly. A Gigli saw is then introduced to lie proximal to the Steinmann pin (Fig. 2c) and a careful check is made to ensure that the sciatic nerve is not too close to the saw.

In revision operations a truly intracapsular osteotomy is not always possible because the notch between the femoral neck and the greater trochanter is usually absent. In such cases the Steinmann pin is introduced before the cholecystectomy forceps, creating a marker for the Gigli saw cut. When the capsule is open, the pin can be identified by touching it with the cholecystectomy forceps. This method was used for the 139 patients in our series having revision operations (Table II).

Table II. Primary surgery and previous operation in 431 patients in the three treatment groups

\begin{tabular}{|c|c|c|c|c|c|c|c|c|c|c|c|}
\hline \multirow[b]{2}{*}{$\begin{array}{l}\text { Method of } \\
\text { attachment }\end{array}$} & \multirow[b]{2}{*}{$\begin{array}{l}\text { Primary } \\
\text { THA }\end{array}$} & \multicolumn{3}{|c|}{ Previous operations other than THA } & \multirow[b]{2}{*}{$\begin{array}{l}\text { Pseud- } \\
\text { arthrosis }\end{array}$} & \multirow[b]{2}{*}{ Other } & \multicolumn{3}{|c|}{ Complications of previous THA } & \multirow[b]{2}{*}{$\begin{array}{l}\text { Fractured } \\
\text { stem }\end{array}$} & \multirow[b]{2}{*}{ Total } \\
\hline & & Osteotomy* & $\begin{array}{l}\text { Hemi- } \\
\text { *arthroplasty }\end{array}$ & $\begin{array}{l}\text { Fractured } \\
\text { neck of } \\
\text { femur }\end{array}$ & & & Dislocation & Infection & Loosening & & \\
\hline Cruciate wire & 45 & 7 & - & 3 & - & 4 & 1 & & 3 & 3 & 66 \\
\hline Double and single wire & 94 & 14 & - & 2 & 4 & 7 & - & 7 & 8 & 3 & 139 \\
\hline $\begin{array}{l}\text { Double wire } \\
\text { and compression spring }\end{array}$ & 77 & 18 & 5 & 5 & 5 & 2 & 4 & 41 & 53 & 16 & 226 \\
\hline Total & 216 & 39 & 5 & 10 & 9 & 13 & 5 & 48 & 64 & 22 & 431 \\
\hline
\end{tabular}


At this stage the hip is flexed, abducted and medially rotated. The Gigli saw is used to cut distally in the line of the femur. The saw strikes and becomes angled over the Steinmann pin, cutting anteriorly and posteriorly and resulting in a two-plane osteotomy (Fig. 2d). The two planes are separated by the Steinmann pin which forms a ridge in the trochanteric bed. Incision of the posteroinferior capsule and the labrum down to the acetabular margin then allows dislocation of the femoral head by adduction of the hip.

At trial reduction the trochanter is replaced onto its bed and held in position with the trident, an instrument which allows correct rotation of the trochanter without fragmentation. Full flexion and at least $10^{\circ}$ of adduction must be possible without displacement of the trochanter. If this is not possible the trochanter is mobilised by dividing the lateral rotators, or the femoral neck is shortened or a prosthesis with a shorter neck is used.

Trochanteric reattachment. Three methods of trochanteric reattachment were tested: the cruciate wire method (Boardman. Bocco and Charnley 1978); the double and single wire method (Boardman et al. 1978); and the double wire and compression spring method. This last method differs from the double and single wire technique only in that the single wire is replaced by one incorporating a compression spring (Fig. 2). The compression spring lies on the front of the neck of the femur; its amplitude is $0.75 \mathrm{~cm}$ and when fully closed it delivers a compression force of about $25 \mathrm{lb}(111 \mathrm{~N})$.

For all three methods the position of the double wire differed from that in the original description to avoid its acting as a single strand over the summit, the weakest part of the greater trochanter. In the current technique the double wire is inserted at the mid-point of the trochanteric bed (which is posterior to the neck of the femur in the coronal plane) distal to the trochanteric bed and brought out through the open neck of the femur. The strands are separated in the sagittal plane and each one is anchored into a small recess in the cut surface of the femoral neck anteriorly and posteriorly. This ensures that the trochanter will be held by the double wire between three fixed points: the loop and the two fixed points on the femoral neck.

The single wire, or the spring wire, is inserted from the front to the back of the neck of the femur through a drill hole at the mid-point between the cut surface of the femoral neck and the vastus lateralis ridge. When the spring wire is used, the spring is made to lie close to the anterior surface of the femoral neck with the loops fully engaged over the spring (Fig. 2e).

At trial reduction all the wires within the medullary canal are moved laterally so that none lie between the stem of the prosthesis and the medial side of the femoral neck.

When the hip is finally reduced, after the cement has set, fixation can be completed. The anterior strand of the double wire is passed over the posterior aspect of the greater trochanter, while the posterior strand is drawn over the anterior surface of the trochanter (Fig. 2f); care is taken that no muscle or soft tissue is trapped between the wire and the trochanter. This cross-over manoeuvre ensures that the wires under tension will run the shortest distance between the fixed points, compressing the trochanter onto its bed.

The posterior strand of the single wire or spring wire is passed through a drill hole in the posterior cortical part of the greater trochanter which overhangs the piriform fossa (Fig. 2f). The wire is close to the femur and it is passed through two cortical layers of the greater trochanter; it does not encroach upon the trochanteric bed.

The double wire is first tightened after passing the free ends through the double loop. The wires are retained in the wire tightener until the compression spring wire is tightened with a second wire tightener. The end point is when the compression spring is fully closed-this can be seen. The wire ends are then twisted, cut short and turned distally to lie at right angles to the wire. If the trochanter is porotic, less compression should be applied. The compression applied by the spring wire slightly relaxes the double wire which is tightened again, usually by half a turn, before the wire is finally twisted off (Fig. 2g).

Postoperative care. Patients with primary LFA are mobilised with support after two days; they progress to sticks or elbow crutches and use them for six weeks. After revision operations patients are kept in bed for two weeks if the revision was for loosening of components or fracture of the stem, and for three weeks if revision was for deep sepsis or recurrent dislocation.

The results of the prospective study are shown in Table III. The minimum follow-up was six months.

Table III. Results in the three groups using different methods of trochanteric fixation

\begin{tabular}{|c|c|c|c|c|c|c|c|}
\hline & Number & \begin{tabular}{l} 
Bony union \\
\multicolumn{1}{c}{-} \\
No loss of \\
position
\end{tabular} & $\begin{array}{l}\text { Slight loss } \\
\text { of position }\end{array}$ & $\begin{array}{l}\text { Fibrous union } \\
\text { No loss of } \\
\text { position }\end{array}$ & $\begin{array}{l}\text { Slight loss } \\
\text { of position }\end{array}$ & $\begin{array}{l}\text { Trochanteric } \\
\text { detachment }\end{array}$ & $\begin{array}{l}\text { Fractured } \\
\text { wires }\end{array}$ \\
\hline Cruciate wire & 66 & 61 & - & 1 & 1 & 3 & 3 \\
\hline $\begin{array}{l}\text { Double and single } \\
\text { wire }\end{array}$ & 139 & 122 & 6 & 1 & 1 & 9 & 11 \\
\hline $\begin{array}{l}\text { Double wire and } \\
\text { compression spring }\end{array}$ & 226 & 218 & 4 & - & 1 & 3 & 8 \\
\hline
\end{tabular}




\section{DISCUSSION}

We regard either detachment or fibrous union of the greater trochanter as failure, and found that a double cross-over wire with a compresson spring gave fewest failures-a rate of $1.8 \%$. The cruciate wire and the double and single wire techniques gave failure rates of $7.6 \%$ and $7.9 \%$ respectively: statistically, they are identical and can be considered together.

The whole series shows that compression spring fixation gives the best results; this is especially so in revision operations where non-union is more likely. The study has also shown the need to replace the trochanter anatomically onto its bed by rotating it posteriorly; if this is done, detachment in flexion is unlikely. However, adduction may lead to loss of bony contact at the distal part of the greater trochanter, and it is for this reason that the trochanter must not be reattached with the hip in an abducted position. Nor should the wires be used to pull the trochanter down to its bed, but only to hold it there; loops, kinks or over-tightening must be avoided. If the trochanter can be held onto its bed without movement, then there is every chance of bony union and the wires are unlikely to fracture. This method has been found neither to prolong the operation time nor to increase the blood loss.

My sincere thanks to Dr R. W. White for his help with the statistical analysis of the results.

\section{REFERENCES}

Boardman KP, Bocco F, Charnley J. An evaluation of a method of trochanteric fixation using three wires in the Charnley low friction arthroplasty. Clin Orthop 1978:132:31-8.

Charnley J. Low friction arthroplasty of the hip: theory and practice. Berlin etc: Springer, 1979:140 5i.

Dall DM, Miles AW. Re-attachment of the greater trochanter: the use of the trochanter cable grip system. J Bone Joint Surg $[B r] 1983$ : 65 B: 559.

Debeyre J, Duliveux P. Les arthroplasties de la hanche: étude critique à propos de 200) cas operés. Paris: Editions Medicales Flammarion. 1954.

del Sel H, Brittain G, Wroblewski BM. Blood loss and operation time in the Charnley low friction arthroplasty. Acta Orthop Scand 1981: 52(2): 197200 .
Markolf KL, Hirschowitz DL, Amstutz HC. Mechanical stability of the greater trochanter following osteotomy and reattachment by wiring. Clin Orthop 1979:141:111 21.

Nutton RW, Checketts RG. The effects of trochanteric osteotomy on abductor power. J Bone Joint Surg $[B r]$ 1984:66 B: 1803

Weber BG, Stühmer G. Improvements in total hip prosthesis implantation technique: a cement-proof seal for the lower medullary cavity and a dihedral self-stabilizing trochanteric osteotomy. Arch Orthop Traumat Surg 1979:93(3): $185 \quad 9$.

Wiesman HJ, Simon SR, Ewald FC, Thomas WH, Sledge CB. Total hip replacement with and without osteotomy of the greater trochanter. J Bone Joint Surg [Am] 1978:60 A:203 10. 